\title{
El retorno antimoderno. Mito y teología política en tiempos postseculares
}

\author{
Ángel Octavio Álvarez Solís
}

1 final de su vida, Reinhart Koselleck escribió acerca de la importan-
cia política de los memoriales de guerra. Con motivo de su visita a Es-
paña en abril del 2005 confirmó la importancia de los monumentos
históricos como una materialización de las disputas por la memoria. En aquella ocasión, el promotor de la historia conceptual indicó la importancia de los intelectuales como "fabricantes de mitos" (mythmaker). Sin embargo, a pesar de su interés por los conceptos y las metáforas, Koselleck no previó la importancia política de los mitos. Al igual que los conceptos, el mito opera como un índice de realidad y factor de cambio socio-político, ya que funciona como un concepto histórico fundamental (Geschichtegrundbegriffe) en la medida que articula la estructura de los espacios de experiencia y delimita los márgenes de los horizontes de expectativa del tejido conceptual de una época. ${ }^{1}$ Por esta razón, el argumento principal de este ensayo destaca la importancia política de los mitos en la formación del debate moderno acerca de la secularización, especialmente la función que los mitos y las teologías políticos desempeñan en la configuración de la semántica política de la modernidad. El ensayo está dividido en tres partes. La primera parte defiende que el mito político constituye el punto ciego de la modernidad. La segunda parte destaca por qué es imposible explicar la secularización sin recurrir a la teología política. Finalmente, la tercera parte describe el retorno del pensamiento teológico en los actuales debates acerca de la secularización. La conclusión es que el mito debe analizarse de manera secularizada y la secularización explicada como uno de los mitos políticos de la modernidad.

1 Cf. Reinhart Koselleck y Michael Jeismann, Der politische Totenkult. Kriegerdenkmäler in der Modern. Múnich, Fink, 1994. 


\section{El mito político: el punto ciego de la modernidad}

Durante casi toda su vida académica, Koselleck consideró que la historia conceptual es un proyecto abierto e inacabado que requiere incorporar elementos que no han sido previstos por el momento metodológico inicial. Algunos de los elementos excluidos del proyecto original de la Begriffgeschichte fueron la metáfora y el mito político. ${ }^{2}$ Hans Blumenberg fue el primero en incorporar algunos elementos ausentes de la versión inicial de la historia conceptual: advirtió que la metáfora constituye un momento de inconceptuabilidad necesario de cualquier orden social. La metaforología es así un complemento de análisis para la semántica histórica. Sin embargo, el problema con esta intersección metodológica reside en que Blumenberg, aunque estudió profusamente el impacto social de los mitos y la textura filosófica de las metáforas, no analizó la dimensión política que adquieren ambas figuraciones tropológicas. Los mitos políticos no son un caso sui generis de metáfora y las metáforas no son elementos accidentales de los lenguajes políticos. Por consiguiente, esta omisión produce un déficit metodológico en la historia de la filosofía política, ya que, desde la perspectiva de la historia conceptual, las metáforas y los mitos políticos son piezas clave del análisis político debido a que constituyen los cimientos simbólicos de una sociedad y de los lenguajes con los cuales se coordina la acción política.

Una amplia sección de la filosofía política contemporánea -especialmente la derivada del postestructuralismo francés y de la teoría de los afectos políticos- es asumida como un pensamiento posfundacional: la imposibilidad teórica de encontrar un fundamento del orden social. Sin embargo, la mitología política es un ejemplo de fundamento contingente del orden político, ya que es capaz de diseminar un sentido social a las acciones tipificadas como políticas. Para advertir la relatividad histórica del pensamiento posfundacional, algunos pensadores analizaron el mito político como un sustrato paleo-politico. ${ }^{3}$ La tesis

\footnotetext{
${ }^{2}$ Algunos de los críticos de la Begriffgeschichte han puesto de manifiesto el carácter abierto del programa de investigación conceptual emprendido por Koselleck y sus seguidores. Hans Blumenberg fue el primero en señalar que la historia conceptual no puede tratar exclusivamente con conceptos políticos, sino que requiere incorporar elementos "inconceptuables" como la metáfora. $C f$. Hans Blumenberg, Paradigmas para una metaforología. Madrid, Trotta, 2003.

${ }^{3}$ El concepto de paleo-política remite a un sentido normativo previo a la institución de un orden social. La paleo-política no es un horizonte de investigación ni una cronología histórica de los acontecimientos políticos: es una hipótesis que permite plantear la existencia de elementos no-políticos previo a la formación de lo político. Por ejemplo, Jacques Rancière es uno de los filósofos que explicó el desacuerdo (la mésentente) como el origen paleo-político de la política. Cf. Jacques Rancière, El desacuerdo. Filosofía y política. Buenos Aires, Nueva Visión, 1996. En sintonía, Jacques
} 
fuerte de este conjunto de argumentos es que el mito configura simbólicamente lo político, pero está expresado semánticamente en la política. ${ }^{4}$ Esto significa que las prácticas sociales y las representaciones históricas de los grupos sociales no proceden necesariamente de un esquema rígido de racionalidad política. La racionalidad política es una forma de cognición contextualizada experimentada por medio de los vocabularios especializados. Tales estudios destacan la dimensión afectiva que compone la razón política, de manera que la estructura de la razón política incluye una dimensión a-racional, afectiva o libidinal, que reintegra el campo de los intereses y las pasiones políticas como un elemento originario del orden civil. El problema con esta aproximación afectiva es que no ha probado con suficiencia la importancia de una conceptualización rigurosa del mito político. ${ }^{5}$ Este último debe ser entendido a partir de una elucidación de la estructura mitológica de la modernidad o, para afirmarlo de manera precisa, el mito político constituye el punto ciego de la modernidad. ${ }^{6}$

Derrida - en crítica al concepto de lo político de Carl Schmitt- planteó a la amistad como el elemento paleo-político fundacional. Cf. Jacques Derrida, Políticas de la amistad. Barcelona, Trotta, 2012.

${ }^{4}$ Cf. Oliver Marchart, El pensamiento político posfundacional. La diferencia política en Nancy, Lefort, Badiou y Laclau. Buenos Aires, FCE, 2009, pp. 55-87.

${ }^{5} \mathrm{El}$ tema de las pasiones y los intereses en relación con lo político ha sido estudiado por diversos autores. Remo Bodei estudió el uso político de las pasiones en el pensamiento político moderno y señaló las razones ilustradas que conducen al menosprecio de las pasiones como parte positiva del conflicto político (R. Bodei, Geometría de las pasiones. México, FCE, 1991). En contraste, Albert Hirschman argumentó que sin el análisis de las pasiones y los intereses no puede comprenderse cabalmente el fenómeno de lo político. Sin embargo, en ambos estudios es evadido el problema del mito político como una de las formas no-racionales y genuinas de lo político. El supuesto de este ensayo es el núcleo afectivo de la racionalidad política: la mitología política como una condición narrativa del acercamiento "pasional, libidinal e interesado" hacia lo político. Véase A. Hirschman, Las pasiones y los intereses. Buenos Aires, Amorrortu, 1977. Actualmente, los teóricos de la posthegemonía como Jon Beasley-Murray, Yannis Stavarakakis y Alberto Moreiras han insistido en el núcleo libidinal, no freudiano, de la práctica política. El mito político es la prueba que demuestra que la política no opera con base en el consenso, sino en los afectos y deseos. Cf. J. Beasley-Murray, Poshegemonía. Teoría política y América Latina. Buenos Aires, Paidós, 2010; A. Moreiras, "Posthegemonía o más allá del principio de placer", en Revista Alter/nativas. Texas, Universidad Estatal de Ohio, agosto, 2013, núm. 1, pp. 1-21; Y. Stavarakakis, "Posthegemonic Challenges: Discourse, Representation and the Revenge(s) of the Real", en Alexandros Kioupkiolis y Giorgios Katsambekis, eds., Radical Democracy and Collective Movements Today. Londres, Ashgate. 2013.

${ }^{6}$ Para el análisis del mito como punto ciego de la modernidad, Eduardo Sabrovsky elucidó la relación filosófica que existe entre el nominalismo y la modernidad. En una veta casi schmittiana, Sabrovsky argumentó que el nominalismo de la modernidad depende, en última instancia, de la excepción y lo extraordinario, pues la modernidad es 
En consecuencia, las razones para impulsar el estudio del mito político, además de ser razones teóricas y empíricas, son razones históricas. El breve siglo $X X$, con sus múltiples guerras, la alta tecnificación burocrática y su comportamiento históricamente anómalo, condujo a que muchas disciplinas cuestionaran la importancia de los sustratos irracionales y a-racionales del poder político. Bajo este contexto teórico, surgieron investigaciones críticas sobre la mitología política, los ritos sociales y la relación performativa entre lenguaje y poder. Por tal motivo, el estudio de los mitos políticos es el cruce interdisciplinario que permite vincular el análisis conceptual con la historia cultural, ya que entendido desde la historia cultural de lo político, el mito político constituye uno de los componentes más fuertes de orientación subjetiva de la política. El mito es una de las formas más excelsas de subjetivación política, por ello su estudio muestra cómo algunas sociedades legitiman el poder político a partir de la proyección de imágenes y narraciones que están dirigidas a la construcción de una identidad afectiva compartida. El estudio del mito supone, entonces, el análisis de la formación subjetiva de las identidades políticas en contextos históricos delimitados.

En Arbeit und Myth (1979), Blumenberg argumentó que el mito es un objeto filosófico cargado de historicidad y estableció la necesidad metodológica de entramarlo en un proceso de trabajo continuo sobre un núcleo narrativo básico: el mitologema. El mitologema es el componente nuclear del mito, ya que otorga el sentido de las acciones de los agentes mitológicos y, por tal motivo, opera como un móvil de la razón práctica. ${ }^{7}$ La conclusión del análisis de

una continua suspensión de las categorías binarias que ella establece para explicarse a sí misma. El mito no explica la modernidad, pero la modernidad depende de los mitos para poder adquirir legitimidad histórica. "La modernidad, en esto consiste su dialéctica profunda, requiere del mito para poder seguir hablando. Pero de lo que habla, primordialmente, es de su radical empresa de desencantamiento: por ello, su compleja dependencia del mito constituye, necesariamente, su punto ciego" (Eduardo Sabrovsky, De lo extraordinario (nominalismo y modernidad). Santiago de Chile, Universidad Diego Portales/Cuarto Propio, 2001, p. 55).

${ }^{7}$ El mitologema es el "núcleo mítico originario" del cual emana el impulso políticosocial de una narración mitológica o, si se prefiere, la condición de posibilidad de la narración mítica. En una perspectiva "sistémica", el mitologema constituye el subnivel narrativo donde se instauran las imágenes y símbolos que componen al mito, $c f$. Alberto de Francisco y Stefanello Grace, "Metodología de identificación de mitos y representaciones en medios de comunicación", en UNIrevista. Madrid, Universidad San Pablo/ Universidad Computense, julio, 2006, vol. 1, núm. 3, pp. 1-12. En Trabajo sobre el mito, Blumenberg introdujo la dimensión temporal en el análisis de la estructura básica del mitologema, y mostró los mecanismos por los cuales un mitologema es reapropiado por una determinada cultura en un periodo histórico delimitado. El análisis de Blumenberg muestra así los procesos en los que mito y narrativa se intersectan para formar un código semántico unificado. En esto último consiste el "trabajo sobre el mito". Cf. H. Blumenberg, Trabajo sobre el mito. Barcelona, Paidós, 2003. 
Blumenberg es que los mitos no sólo nombran cosas, sino que fundamentan el estado de cosas, puesto que establecen las condiciones para la significatividad de las acciones sociales. El mito es así el sustrato simbólico del orden social porque las acciones con sentido adquieren una dimensión social en el momento que son codificadas por una narración mitológica. Por lo tanto, el mito no debe ser analizado como un objeto histórico ni como un gesto histórico, sino como un proceso de construcción narrativa y significación temporal de las acciones políticas fundamentales.

Los estudios clásicos sobre el mito político son relativamente escasos en comparación con los estudios filosóficos acerca del mito en general. Tales estudios destacan la doble propiedad del mito político: una función crítica y una función reaccionaria. ${ }^{8}$ Ernst Cassirer fue uno de los primeros filósofos que tipificó el mito político como un elemento regresivo, tradicionalista y totalitario. Para un filósofo preocupado por la filosofía de las formas simbólicas, el mito político es el resultado de una imaginación política exuberante y personalizada: el deseo colectivo personalizado. Por esta razón decisionista, el mito político es un instrumento retórico colindante con la política fascista. ${ }^{9}$ En contraste, George Sorel argumentó que el mito político es un recurso progresista capaz de promover la acción colectiva. Según Sorel, los motivos que incitan a la acción colectiva no pueden ser explicados y transferidos sin el poder de convocatoria del mito político: el mito opera con la misma fuerza que la religión porque es la objetivación del deseo de la voluntad colectiva y, por esta razón, debe ser considerado como un elemento progresista de la historia humana. ${ }^{10}$ Finalmente, Carl Schmitt fue quien mejor expresó la carga política del mito en relación con la formación histórica del enemigo político. En un texto temprano, Schmitt publicó La teoría política del mito (1923) en la que, a diferencia de Cassirer y en sintonía con Sorel, explicó que no existe algo del orden social con más potencia política que el mito de la nación. Contra el déficit mitológico del parlamentarismo liberal o del materialismo bolchevique, el mito político es fuerza política unificadora, ya que es el equivalente al politeísmo de la teología política, pues encauza la pluralidad humana en un universo de sentido compartido: "la teoría del mito es la expresión más poderosa de la considerable pérdida de evidencia del racionalismo relativo del pensamiento parlamentario [...] Las homogeneidades terminantes,

${ }^{8}$ La teoría clásica del mito político consiste en mostrar al mito como un elemento anómalo y profuso de las prácticas políticas modernas, como un recurso irracional del poder político.

${ }^{9}$ Vid. Ernest Cassirer, El mito del Estado. México, FCE, 1983.

10 "Hay que juzgar a los mitos como medios de actuar sobre el presente: toda discusión acerca de cómo aplicarlos materialmente al transcurso de la historia carece de sentido" (George Sorel, Reflexiones sobre la violencia. Madrid, Alianza, 2005, p. 180). 
que subsisten en partes todavía, se disuelven en el pluralismo de un número incalculable de mitos". ${ }^{11}$

El problema con las teorías canónicas del mito político es que aseguran que el mito contiene una función política evidente que no requiere una justificación política. El mito no es un objeto político con una sustancia política superpuesta, sino un tropo potencialmente politizable: el mito necesita de una activación afectiva. La activación política ocurre cuando una colectividad cuenta con la suficiente fuerza de concertación o cuando un líder carismático comunica a la multitud el pathos de la fuerza política condensada en una imagen productora de efectos posthegemónicos. ${ }^{12}$ Esto significa que la relación entre política y subjetividad establecida por el mito no pasa necesariamente por una relación libidinal con lo político, sino por una apertura política a la esfera de lo libidinal. La política es convertida en el sustrato de las pasiones y los afectos, pero no a la inversa. En consecuencia, la teoría canónica del mito fracasa porque no puede dar cuenta de esta apertura posthegemónica del mito y, por ende, únicamente destaca el rasgo irascible del mito sin distinguir su dimensión narrativa o su composición normativa.

No obstante, aunque la teoría canónica del mito político es insuficiente para explicar la fuerza política de los afectos mitológicos, es necesaria como un primer momento en la elaboración de una teoría crítica del mito político. Si la teoría crítica requiere destacar la dimensión narrativa y afectiva del proceso de apropiación temporal de un mito, existe entonces una conexión necesaria entre el mito, la narración, el tiempo y los afectos. El mito es subsidiario de la narración y el tiempo es experimentado, durante el proceso mitológico, como un afecto intemporal, como una pasión originaria. Por esta razón, no toda narración trabaja necesariamente sobre un mito, ni todo mito es capaz de captar las pulsiones políticas. La narración es el vehículo mediante el cual es transportado el mito político, pero el mito no comunica a priori un afecto o una pulsión política. ${ }^{13}$

${ }^{11}$ Carl Schmitt, "Teoría del mito político", en Zarka Charles Yves, Carl Schmitt o el mito político. Buenos Aires, Nueva Visión, 2010, p. 152.

12 "La mitología política queda realizada, in-corporada, convertida en disposición permanente, una forma duradera de pararse, hablar, caminar y por consiguiente de sentir y de pensar" (Pierre Bourdieu, The Logic of Practice. Cambridge, Polity, 1990, pp. 69-70).

${ }^{13}$ Clara Bottici es una filósofa preocupada por el mito político y realizó una definición operativa en la que articula narración, mito y sociedad. En The Philosophy of Political Myth, señaló: "Mito político es el trabajo sobre una narrativa común por las cuales los miembros de un grupo social (o la sociedad), para poder comunicarse, hacen significativas sus expresiones y hazañas" (Clara Bottici, The Philosophy of Political Myth. Cambridge, Universidad de Cambridge, 2007, p. 133). El problema con esta aproximación es que, aunque trasciende la teoría canónica del mito político, no fundamenta el uso del tiempo por parte de la mitología política ni estudia el impacto libidinal de la mitología política. 
Debido a este déficit teórico, considero que el mito político debe ser entendido como una figura retórica posthegemónica capaz de instituir las condiciones simbólicas para que, por medio del control del tiempo histórico, una colectividad o un líder carismático funde una relación afectiva con el poder político. Por consiguiente, el mito político es el proceso de orientación afectiva mediante el cual los miembros de un grupo social, o de un conjunto amplio de la sociedad, trabajan sobre una narrativa común para disponer de los medios simbólicos y libidinales más eficaces para controlar el tiempo histórico y producir una identidad política compartida. Esta aproximación posthegemónica permite advertir que, en el proceso de subjetivación de la narrativa común del mito, los diferentes grupos políticos y los agentes sociales se disputan la significación política del mitologema. En esta querella semántica, los grupos políticos asumen una identidad política acorde con la narración del mito y, con ello, surgen las condiciones simbólicas y afectivas que permiten postular la diferencia política esencial: la distinción entre amigos y enemigos.

La distinción amigo-enemigo genera que el mito político sea justificado como un significante vacío: la indeterminación relativa del mito es lo que posibilita la transmisión de los procesos afectivos de la legitimidad política. Para que esta transmisión sea posible, el mito debe comunicarse en tres esferas diferenciadas: (i) una fundamentación cognitiva, (ii) una pretensión práctica y (iii) una manifestación estética. Para el primer caso (i), los mitos políticos sirven para trazar un mapeo del mundo social en el que están inmersos los sujetos políticos, puesto que son capaces de reducir la complejidad de la vida social debido a un esquema cognitivo. La complejidad del orden social queda subsumida por la explicación mitológica, la cual está constreñida por un marco teórico reducido y manipulable por el observador. El análisis mitológico es así una codificación sistémica de lo social. ${ }^{14}$ Para el segundo caso (ii), los mitos políticos incentivan la compulsión a la acción, ya que requiere de la representación de las acciones posibles en una secuencia narrativa donde se justifiquen las acciones emprendidas en el presente. La formación de un mito político no implica una narración simple de los eventos posibles, sino la construcción de significantes históricos que promueven la acción política

${ }^{14}$ Niklas Luhmann argumentó que cualquier teoría social que se precia de ser ampliamente explicativa debe ser capaz de reducir la complejidad a su máximo para así llegar a una mejor comprensión de lo social. Desde una perspectiva sistémica, la mitología política opera como un subsistema que comunica el imaginario social y, por ello, forma parte de un subsistema del sistema político. En este sentido "sistémico", Tudor ha destacado el papel cognitivo del mito político al señalarlo como una forma simbólica que permite describir la fundamentación del mundo. Tudor escribió: "un mito en el cual se narra la historia de una sociedad política", lo cual permite la descripción de los criterios y los valores políticos que fundamentan el orden civil (Henry Tudor, Political myth. Londres, Preager, 1972, p. 138). 
duradera como la profecía teológica, el mesianismo político o la memoria histórica. El mito político mantiene una dimensión pragmática al configurarse como una ideopraxis. ${ }^{15}$ Finalmente (iii), si los mitos políticos son narrativas que describen y transforman el mundo, tales mitos desarrollan una secuencia de acontecimientos en narraciones que tienen la propiedad de articularse mediante formas dramáticas, afectivas y tropológicas. El mito político confirma que si existe narración, existe una tropología histórica y, si tal tropología adquiere una dimensión política, entonces surge un efecto libidinal. Como afirmó Lincoln (1989), en la articulación entre la trama narrativa y el pathos de lo político emerge el mito político como una síntesis dramática.

Por último, el análisis del mito político mantiene una relación directa con la teoría política de los afectos. Esta teoría sostiene la existencia de condiciones afectivas o libidinales que permiten explicar los procesos de subjetivación política. ${ }^{16}$ El problema reside en que la mayoría de estas teorías destacan las condiciones trascendentales de los afectos y el deseo en la formación, la transferencia y la aplicación simbólica del poder político, pero olvidan el potencial político del mito y, por extensión, el poder mistificante de la política. Por esta razón, la investigación de los mitos políticos no tiene la pretensión de situarse deconstructivamente como el otro lado de la razón política ni afirmar un modelo de análisis que se antepone a una imagen estrictamente racional de lo político. Por el contrario, el análisis de la mitología política expone por qué la racionalidad política sirve para la construcción y la difusión de mitos, símbolos y ritos, con los cuales los mecanismos de poder son transmitidos y subjetivados por los diversos grupos sociales. La premisa principal de mi argumento es que ninguna época histórica es la excepción al uso político de los mitos. En las sociedades tradicionales o religiosas, el vínculo entre el símbolo, el mito y la política está mediado por una proximidad entre la religión y el poder. En estas sociedades, la mitología política es subsidiaria de una forma de teología política. ${ }^{17}$ En cambio, en las sociedades modernas

${ }^{15}$ Los mitos políticos, en su dimensión pragmática pueden ser entendidos como ideopraxis, como ideas que incitan a la acción. Desde esta perspectiva, los mitos políticos no sólo buscan describir el mundo, sino transformarlo. George Sorel, quien mejor detectó el aspecto pragmático del mito político, afirmó: "el mito no debe ser juzgado como un almanaque astrológico que narra lo que seguirá en el futuro, sino un evento significativo para actuar sobre el presente" (G. Sorel, op. cit., p. 180).

${ }^{16}$ Pierre Bourdieu detectó la configuración emotiva del habitus que determina el comportamiento nuclear de algunos grupos antagónicos. Sin embargo, la teoría política de los afectos puede encontrarse de manera amplia en J. Beasley-Murray, op. cit.

${ }^{17} \mathrm{Al}$ respecto, destaco el estudio seminal de Ernst H. Kantorowicz (The King's Two Bodies, 1957), los estudios pioneros de Marc Bloch (The Royal Touch, 1973) y las aportaciones socio-históricas de Norbert Elias (Uber den Process der Zivilisation, 1977). 
existe la tentación de sospechar de la desaparición de los mitos políticos o, en tal caso, en asumir que sólo son reductos tradicionalistas y reaccionarios de los regímenes totalitarios que identificaron al siglo xx. Sin embargo, en las sociedades contemporáneas o postseculares, el mito político es un elemento difuso, inasible y oculto, ya que su posible ubicuidad cuestiona radicalmente los supuestos fundacionales de la modernidad al encender nuevamente la querella de la secularización. ${ }^{18}$ En definitiva, si el mito político es el punto ciego de la modernidad y la secularización es la máxima manifestación de la lucha política por la modernidad, entonces no es posible explicar la relación entre secularización y modernidad sin la intervención del mito político. El mito político debe explicarse de forma secularizada y la secularización debe ser entendida como uno de los mitos de la modernidad.

\section{La dialéctica de la (post)secularización}

El debate acerca de la secularización es un debate inscrito en la pérdida de la ilusión weberiana: un mundo en el que la racionalidad instrumental y la

${ }^{18} \mathrm{La}$ argumentación liberal canónica y la defensa multicultural tradicional coinciden en afirmar la hipótesis sociológica acerca de la avenencia de la sociedad postsecular. Por ejemplo, Jürgen Habermas y Charles Taylor argumentaron que la sociedad actual está en una situación postsecular debido a que la modernidad ha entrado en conflicto con los principios básicos que la constituyen como programa político. Esto significa que el diagnóstico weberiano del desencantamiento del mundo falló respecto de las expectativas y las promesas incumplidas de la modernidad; sin embargo, el paradigma postsecular no implicó la negación de la teología política en el campo teórico, o el crecimiento del fundamentalismo religioso en el terreno político. Como señaló Mark Lilla, la sociedad contemporánea está en una nueva querella por la secularización debido al surgimiento de una nueva teología política. Cf. Mark Lilla, The Stillborn God. Religion, Politics, And The Modern West. Nueva York, Vintage Books, 2007. La conjetura que sostengo es que la teología política nunca pudo erradicarse de la modernidad porque forma parte de su horizonte político. En la Edad Media o en la Antigüedad no existe teología política, ya que lo que opera es una política basada en fundamentos religiosos o naturales; sin embargo, la modernidad persigue el sueño fundamentador no por la nostalgia de los viejos fundamentos -Dios, la historia o la sociedad sin clases- sino porque la política moderna carece de fundamento debido a las características del acto democrático. La democracia es un espacio vacío, un fundamento no fundamentado que requiere del contrato y la legitimación constante de la sociedad política. Contrario a lo que argumentan los liberales kelsenianos, el fundamento del acto democrático no reside en la norma fundamental (constitución), ni como pensaron los republicanos salvajes, en el plebiscito permanente: el acto democrático es infundante porque cada sociedad atribuye un pacto fundacional basado en un fundamento contingente. La democracia es así un espacio constante de discusión permanente en el que nunca se suprime el conflicto y el antagonismo latente surgido por la misma dinámica democrática. 
técnica forman parte de un principio general de equivalencia. La secularización supuso una pérdida del sentido, una nostalgia por el absoluto y una reacción teológica, ya que, desde su aparición semántica, el concepto está cargado de una filosofía cristiana de la historia. En su origen tardo-medieval, la secularización fue una estrategia de discusión teológica en la que estuvieron previstos los conflictos inmanentes de la política moderna: el disenso por la falta de un origen compartido o, como explicó el teólogo Erik Peterson en discusión con Carl Schmitt, la imposibilidad moderna del monoteísmo político. ${ }^{19}$

Inicialmente, el concepto de secularización adquirió una dimensión jurídica en la primera ola de la modernidad. La primera aparición semántica ocurrió en Francia en el siglo XVI y advirtió el tránsito del clero regular al clero secular tipificado por el derecho canónico. ${ }^{20}$ Posteriormente, el término amplió su significado jurídico por una concepción política que implicó la expropiación de las propiedades y los bienes eclesiásticos. Esto último fue consecuencia de la Paz de Westfalia: se discutió ampliamente la legitimidad acerca de la jurisdicción de las tierras y los bienes de la Iglesia católica apropiados por los protestantes. Por último, el concepto sufrió una transformación radical con la filosofía de la historia derivada de la Revolución francesa de 1789: la secularización, como el progreso o la emancipación, son las categorías que hacen inteligible el curso de la historia y, por esta razón, el fin último al que tiende la historia de la humanidad. ${ }^{21}$ Por consiguiente, los tres momentos históricos de la secularización $-a$ ) el jurídico-canónico, $b$ ) el jurídico-político y c) el hermenéutico-filosófico- confluyeron en el siglo XVIII para mostrar la legitimidad de los tiempos modernos, para destacar la dirección ilustrada de los tiempos modernos.

Max Weber fue el primero en plantear el problema filosófico de la secularización con base en la dialéctica entre el desencantamiento del mundo (Entzauberung der Welt) y el incremento de la tecnificación burocrática. ${ }^{22}$ La salida del diagnóstico weberiano supone la explicitación de la estructura profunda del ethos moderno y la separación de las esferas de acción. ${ }^{23}$ El ethos de la modernidad indica la autoafirmación antropológica de la autonomía

${ }^{19}$ Cf. György Geréby, "Political Theology versus Theological Politics: Erik Peterson and C. Schmitt", en New German Critique, noviembre, 2008, vol. 35, núm. 3, pp. 7-33.

${ }^{20} \mathrm{Cf}$. Werner Conze, "Säkularisation, Säkularisierung", en O. Brunner, W. Conze, R. Koselleck, eds., Geschichtliche GrundBegriffe. Historisches Lexikon zur Politisch-sozialen Sprache in Deutschland. Stuttgart, Klett Cotta, 1984, vol. 5.

${ }^{21}$ Cf. Giacomo Marramao, Cielo y tierra. Genealogía de la secularización. Barcelona, Paidós 1998, pp. 12-34.

${ }^{22}$ Cf. Marx Weber, El político y el científico. Madrid, Alianza, 2002, p. 55.

${ }^{23} C f$. José Luis Villacañas, "Ethos y economía: Weber y Foucault sobre la memoria de Europa”, en Daimon. Revista Internacional de Filosofía. Madrid, Universidad Complutense, Facultad de Filosofía y Letras, septiembre, 2010, núm. 51, pp. 25-46. 
del ser humano respecto de la religión o de la naturaleza. Por esta razón, el problema de una modernidad postweberiana es posible sólo en respuesta al dilema sociológico de la secularización: prevalece el diagnóstico weberiano sobre el paulatino desencantamiento del mundo o existe una renovación de la mitología anclada en la reactivación de la teología política, la formación de una filosofía de la historia del capital financiero y la aparición de un milenarismo neoliberal. El retorno de lo religioso a la esfera pública es así un síntoma de la imposible separación entre las creencias religiosas y los principios políticos. Por consiguiente, la explicación weberiana resulta insuficiente, ya que el mito político re-encanta un mundo desorientado que ha sido diagnosticado constantemente por una crisis, el cual convierte el tema del mito en un problema del ethos moderno.

Los mitos políticos surgen, entonces, como una respuesta filosófica a una crisis histórica. La época contemporánea no es la excepción. Sin crisis no existe modernidad, pues la legitimidad de la modernidad depende del significado que la crisis le otorgue: la modernidad es un tiempo histórico intermitente y elusivo porque sólo puede ser identificado en pugna con lo viejo y en apertura con lo nuevo. La legitimidad es posible cuando el tiempo histórico del presente (Neuzeit) es colocado en crisis con un periodo histórico previo o futuro: un futuro-pasado. ${ }^{24}$ Por lo tanto, la legitimación de los tiempos modernos supone una forma parcial de interrupción de la crisis y, al mismo tiempo, una activación de la mitología como una respuesta metahistórica a los problemas planteados por la secularización. ${ }^{25}$ La crisis es la forma de la conciencia moderna y el mito reduce la complejidad de la crisis, pero la crisis no es capaz de reducir el desencanto ocasionado por la secularización. Por lo anterior, cabe preguntarse ¿cómo es posible que la secularización sea un incentivo para la activación de la mitología política si está basada en una continua desmitologización del mundo? ¿Por qué la modernidad puede sostenerse mediante una estructura mitológica? ¿La modernidad, los mitos y la secularización son necesariamente incompatibles?

Para responder el dilema sociológico acerca de la reactivación de las mitologías políticas de la modernidad destaco dos estrategias. La primera, la estrategia sociológica, consiste en lo siguiente: si la política moderna tiene como premisa básica el incremento de la razón instrumental y la consecuente tecnificación burocrática, este tipo de racionalidad parecería inmune a la influencia de los mitos políticos. Por consiguiente, la jaula de hierro moderna construida por los especialistas sin espíritu no defiende la existencia de la necesidad del sím-

${ }^{24}$ Cf. Reinhart Koselleck, Aceleración, prognosis y secularización. Valencia, Pretextos. 2003, pp. 37-47.

${ }^{25} \mathrm{Cf}$. H. Blumenberg, Trabajo sobre el mito. 
bolo y el mito, por lo cual en su descripción los mitos aparecen evaluados como elementos estrictamente premodernos. ${ }^{26}$ La segunda alternativa, la estrategia filosófica, afirma que la modernidad no implica la disolución de las narrativas mitológicas; por el contrario, la modernidad está cimentada en una mitología secular, en el mito del progreso y la razón científica, estableciendo con ello la dialéctica de la Ilustración. ${ }^{27}$ En consecuencia, si es verdad que la modernidad es una mitología en la que, desde sus fundamentos, no es posible erradicar el elemento mitológico que la compone, entonces es necesario que la narrativa de la razón universal no cumpla su propósito emancipatorio. Frente a este dilema, entre el debilitamiento del mito ocasionado por el desencantamiento del mundo y la secularización inevitable de los mitos tradicionales, resulta relevante optar por una tercera posición que permita comprender la capacidad explicativa y orientadora del mito sin que ello niegue el proceso secular: la politización de las estructuras mitológicas de la modernidad.

La politización de las estructuras mitológicas no supone un abandono del programa emancipatorio de la modernidad ni una reactivación de la teología política; por el contrario, la politización del mito es una renovación crítica del debate acerca de la secularización, ya que pone en cuestión el vínculo artificial entre la política y la religión. Por esta razón, para conseguir el viraje político del análisis mitológico es necesario asumir tres demarcaciones normativas. Primero, el estudio de los mitos políticos permite analizar las dimensiones simbólicas profundas del poder político. Segundo, el estudio político de estos objetos evita la falacia etnográfica, la cual consiste en una identificación entre mito, símbolo y rito. ${ }^{28}$ Tercero, la investigación mitológica sitúa el mito político en el mismo registro histórico que los conceptos y las metáforas, ya que operan como índices de realidad y factores de cambio político. Junto con las metáforas y las narraciones fundacionales, los mitos políticos forman reductos semánticos que dan cuenta de los cambios históricos acontecidos en una sociedad política. El análisis mitológico detecta la función simbólica de la codificación política porque permite la diferenciación entre la política y lo político. La política registra los fenómenos políticos observables de la moder-

${ }^{26}$ Para una mayor profundización de la lectura weberiana acerca de los mitos políticos: Antonio Rivera García, "Los mitos políticos: las patologías modernas de la res publica", en Revista Teoría/Crítica, 1999, núm. 6, pp. 99-125, y Raina Zimmering, "El mito político de la RDA", en Comunicação \& política, 2000, núm. 1, pp. 9-21.

${ }^{27} C f$. Theodor Adorno y Max Horkheimer, Dialéctica de la Ilustración. Madrid, Trotta, 1998.

${ }^{28}$ Aunque existe una relación estrecha entre el mito, el símbolo y el rito, ello no implica que los mitos se reduzcan a su manifestación externa. Si todo mito se construye mediante símbolos, ritos e íconos, no todo símbolo o rito es capaz de producir un determinado mito político. $C f$. Jean Cazeneuve, Sociología del rito. Buenos Aires, Amorrortu, 1971. 
nidad y lo político disputa los fundamentos contingentes que hacen posible el orden social. Esto supone que el análisis del mito político posibilita la diferencia onto-teológica entre la politique y le politique según el uso sustantivo, crítico o reflexivo del mito en un contexto histórico singular.

La distinción anterior es más que un límite metodológico: la diferencia onto-teológica entre la política y lo político supone una revisión mitológica de la modernidad, pues la legitimidad o ilegitimidad de los tiempos modernos depende de la teorización del uso político de los mitos y, en última instancia, de la disolución del teorema de la secularización. Carl Schmitt y Claude Lefort fueron los teóricos que difundieron el teorema de la secularización, pues a partir de la definición del concepto de lo político lo teológico adquiere una dimensión política. ${ }^{29}$ El teorema de la secularización es así la pregunta por la legitimidad, política o conceptual, de la transferencia del contenido de los conceptos religiosos a los conceptos políticos. Sin la revisión de la estructura mitológica de la modernidad, emerge la reactivación de la teología política y, con esta reactivación, la confirmación del teorema de la secularización, puesto que aparece un principio general de equivalencia entre lo teológico y lo político. ${ }^{30}$ Para salir de este dilema fatal -lo teológico o lo político- es necesario precisar el intento de conjura del mito como un síntoma político de la modernidad. El síntoma registra los efectos antimodernos de una secularización completamente imposible. Por lo tanto, la modernidad no es sólo un concepto normativo como lo pensaron los progresistas liberales, ni tampoco una metáfora catacrética como lo defendieron los reaccionarios antimodernos: la modernidad es una estructura narrativa y, por extensión, una sedimentación mitológica que dota de sentido político a las acciones emancipadoras y reaccionarias. El núcleo mitológico de la modernidad es capaz de codificar, en una narrativa, la pervivencia reaccionaria junto con la pulsión liberadora para generar que las acciones históricas tengan un sentido de unidad. La filosofía ilustrada de la historia y la crítica antiliberal de los contrarrevolucionarios

${ }^{29}$ Cf. Bernard Flynn, The Philosophy of Claude Lefort: Interpreting the Political. Evanston, Universidad del Noroeste, 2005; A. Rivera Gracía, El Dios de los tiranos. Un recorrido por los fundamentos teóricos del absolutismo, la contrarrevolución y el totalitarismo. Córdoba, Almuzara, 2007.

${ }^{30}$ La estrategia "post-Blumenberg" evita fundamentar lo político en lo teológico tal y como lo realizaron los antimodernos contemporáneos como Carl Schmitt, Karl Lowith, Leo Strauss y Eric Voegelin. Mi propósito consiste, entonces, en proponer una alternativa no-teológica a la fundamentación última de lo político sin que ello implique negar la mitología y la teología. Esta estrategia posfundacional está lejos del planteamiento de Marchart, pero recupero la importancia de los análisis de Claude Lefort y Jean-Luc Nancy respecto del lugar vacío del poder político. El punto fino es partir de la imposibilidad de todo fundamento último, ya que el análisis de los mitos políticos muestra la importancia de optar por una pluralidad de fundamentos contingentes y transitorios del acto político. 
son, de esta manera, la puesta en escena del mitologema de la modernidad: la querella de la secularización como un síntoma de la falta de fundamento.

La relación entre la secularización y la ausencia de fundamento ha sido conceptualizada por muchos juristas desde Carl Schmitt para quien los conceptos políticos modernos son conceptos teológicos secularizados hasta Ernst Kantorowickz para quien los conceptos teológicos, antes que ser secularizados, son modificaciones del derecho imperial a la teología. ${ }^{31}$ La teología política constituye, por lo tanto, la piedra angular de la secularización, ya que la pregunta moderna por el fundamento de lo político sólo puede ser respondida por la teología en la medida que lo político no es un campo de saber autorreferencial. Lo político es autónomo, pero no independiente de las múltiples esferas de acción de la modernidad. Esto implica que si la teología política nunca se ha ido del imaginario moderno es porque forma parte sustantiva de ese imaginario. Ni la política medieval ni la política antigua tienen teología política, pues para estas épocas el problema del fundamento está resuelto por la religión o por la naturaleza. En cambio, la modernidad mantiene el sueño de fundamentación absoluta no por la nostalgia de los viejos fundamentos (Dios, la historia, el contrato social o la sociedad sin clases), sino porque la política moderna carece de fundamento debido a las características del acto democrático. ${ }^{32}$

Jean-Claude Monod reconstruyó la querella acerca de la secularización y encontró dos sentidos antagónicos del concepto: la secularización como transferencia de contenidos teológicos a la esfera temporal y la secularización reducida a la liquidación de la herencia cristiana. La primera forma conduce al laicismo; la segunda, a la emancipación de la religión. ${ }^{33}$ El problema que encuentra Monod es que la teología política no puede ser moderna debido a que está unida a formas de dominación carismática, y la secularización, inevitablemente, conduce a una dominación legal-racional. Sin embargo, la formación de la legalidad puede ser carismática y la racionalidad puede transmitirse con mecanismos carismáticos. Por ejemplo, el patriotismo de

${ }^{31}$ Cf. Hermann Kantorowickz, Los dos cuerpos del rey. Un estudio de teología política medieval. Madrid, Alianza, 1985; C. Schmitt, Teología política. Madrid, Trotta, 2011.

${ }^{32} \mathrm{La}$ democracia es un espacio vacío, un fundamento no fundamentado, que requiere del contrato y legitimación constante de la sociedad. Por consiguiente, el fundamento del acto democrático no radica en la constitución o en el kerygma del pueblo -tal y como lo argumentaron Kelsen y Schmitt- sino en la apertura permanente de lo social. El acto democrático es más que un plebiscito cotidiano y menos que un poder destituyente, porque cada sociedad construye un pacto político fundacional basado en un fundamento social contingente. La democracia es así el espacio constante de la discusión continua en el que nunca se suprime el conflicto ni se excluye el antagonismo latente surgido por la dinámica democrática.

${ }^{33} \mathrm{Cf}$. Jean-Claude Monod, La querelle de la sécularisation. De Hegel à Blumenberg. París, Vrin, 2002. 
la constitución defendido por el Estado liberal de derecho es una forma de carisma de la legalidad debido a que la identificación entre el orden legal y la promoción del bien común es transmitida mediante la motivación carismática de la cultura republicana. Análogamente, la racionalidad política supone una derivación carismática en el momento en el que las demandas sociales pueden ser materializadas en símbolos enarbolados por un líder o por una consigna política. El carisma no es incompatible con la racionalidad instrumental o con la racionalidad con arreglo a fines. Al respecto, Rudolph Sohm, el teólogo protestante de quien Weber retomó el concepto de autoridad carismática, mostró que la creencia religiosa está basada necesariamente en el carisma y, por consiguiente, que la organización de las creencias religiosas es incompatible con la legalidad jurídica, pues está fundamentada en una organización carismática. ${ }^{34}$ Por consiguiente, la incompatibilidad aparente entre la dominación carismática y la dominación legal-racional es más una deriva normativa de la secularización que una distinción analítica de la teoría weberiana de la modernidad: la dominación debe ser legal-racional porque, de facto, no es ni puede serlo dadas las condiciones carismáticas de la hegemonía moderna.

Para evadir la dialéctica de la secularización -la tensión entre el abandono de la religión en el ámbito de las explicaciones científicas y el resurgimiento de elementos religiosos en el espacio público-, la argumentación liberal y la defensa multicultural coinciden en afirmar la hipótesis sociológica acerca del surgimiento de la sociedad postsecular. La sociedad postsecular es la forma sociológica de pensar la persistencia o el resurgimiento de la religión en las prácticas del presente. El punto crítico es que la definición de lo postsecular coincide con los dos sentidos de secularización propuestos por Monod, incluso los lleva al límite al plantear el problema de si la sociedad moderna fue secular o si nunca lo ha sido. Si la sociedad moderna es secular, entonces la actual revitalización de la religión en la esfera pública conduce a un contexto postsecular. En cambio, si la sociedad moderna nunca ha sido secular, la recuperación de la religión es un síntoma más que un dato empírico. La defensa de una sociedad postsecular ha sido tematizada principalmente por Jürgen Habermas y Charles Taylor, quienes argumentaron que la sociedad actual está en una situación postsecular debido a que la modernidad ha entrado en conflicto con los principios básicos que la constituyen como programa político. Esto significa que el diagnóstico weberiano del desencantamiento del mundo falló respecto de las expectativas y las promesas incumplidas de la modernidad; sin embargo, el paradigma postsecular no implica la negación de la teología política en el campo teórico ni el crecimiento del fundamentalismo religioso en el terreno

${ }^{34}$ Cf. Peter Haley, "Rudolph Sohm on Charisma", en The Journal of Religion 60. Universidad de Pensilvania, abril, 1980, núm. 2, pp. 185-197. 
político. En contraste, Marcel Gauchet y William Cavanaugh afirmaron que la sociedad moderna no es secular, puesto que la relación entre la política y la religión radica en la estructura originaria del Estado constitucional de derecho y, sobre todo, porque el mito del Estado como salvador no logró incorporarse en las lógicas modernas. ${ }^{35}$ Por lo tanto, la sociedad contemporánea está en una nueva querella por la secularización, más por el rehabilitamiento de la religión en el ámbito público que por el surgimiento de una nueva teología política. Las teologías políticas postseculares son las secuelas de una forma de pensamiento político que postula la imposibilidad de fundamentar la política fuera del horizonte religioso. Lo novedoso es que tales teologías no implican un compromiso confesional o una militancia religiosa.

No obstante, los debates entre la teología política y la crítica a la modernidad surgieron desde la primera aparición de lo moderno. Ya en la querelle des anciens et dens modernes, la ruptura de lo nuevo implicó una crítica al retraso cultural de los antiguos y un rechazo al afán de novedades de los modernos. En 1688, Charles Perrault publicó Parallèle des anciens et des modernes y, con este texto, se inauguró una serie de preceptivas literarias que intentaron mistificar o rechazar los aportes del mundo moderno en el campo de la estética. Sin embargo, la crítica política a la modernidad surge, en sentido estricto, con los filósofos antimodernos.

Los antimodernos fueron los publicistas que mejor pensaron en la imposibilidad de la secularización del poder político, principalmente, por dos razones. Primero, los antimodernos sostienen que la política moderna está basada en la catástrofe, el desorden y la falta de autoridad. Segundo, los antimodernos suponen que la religión es la única esfera de acción que es capaz de producir un orden basado en la autoridad. Por un lado, los filósofos antimodernos -los cuales pueden ser enmarcados como reaccionarios, contrarrevolucionarios o totalitarios- anticiparon las "calamidades modernas" del ejercicio público de la razón porque el principio de autoridad de los antiguos fue sustituido por el principio de legitimidad de los modernos. Por otro lado, los antimodernos son anti-ilustrados y, por esta razón, no deben confundirse con los reaccionarios ni con los antiliberales, puesto que los antimodernos realizaron una crítica anti-ilustrada de la modernidad porque encuentran, en la tradición y en la religión pública, los elementos de restauración de una estabilidad perdida por la fuerza histórica de la Ilustración. Para los antimodernos, la Ilustración no es amiga o enemiga de la modernidad: la Ilustración es el triunfo de la burguesía como la clase social hegemónica. La antimodernidad es la pérdida de la orientación política en clave aristocrática, pues la burguesía no tiene una religión

${ }^{35} \mathrm{Cf}$. William Cavanaugh, "La mitología de la modernidad: un diagnóstico teológico", en Carmen Bernabé Ubieta, ed., La modernidad cuestionada. Bilbao, Universidad de Deusto/Instituto Diocesano de Teología y Pastoral, 2010. 
pública, ya que se convirtió en el portavoz más relevante del nacionalismo. ${ }^{36}$ Por consiguiente, un antimoderno será aquel que, sin dejar de ser moderno, separa la modernidad de la Ilustración y distingue a la secularización del desencantamiento del mundo. Para decirlo en un vocabulario político, un antimoderno no puede abandonar el impacto social de la teología política porque considera que la religión, como fundamento político, nunca se ha ido ni podrá desterrarse, pues configura la identidad política de la conciencia moderna. Al igual que con el uso político del mito, los antimodernos sostienen una forma desmesurada de teología política, ya que argumentan que la religión puede servir como un instrumento conservador o como un elemento emancipatorio siempre y cuando el laicismo no devenga en un jacobinismo radical. ${ }^{37}$

En consecuencia, por teología política debe entenderse el conjunto de problemas referidos entre la producción política de una teología civil y la manifestación civil de una política religiosa. Esto significa que el problema de fondo de la teología política es la preocupación del valor de la tradición cristiana para la política y no a la inversa, como pensó Carl Schmitt: la preocupación por el valor político del catolicismo. La teología política está orientada por la comparación y la transferencia productiva entre la política y la religión. Por esta razón, aunque la teología política tiene un origen semántico en la Civitas $D e i$ de san Agustín y una reactivación política en la filosofía reaccionaria del siglo XIX, la teología política es más que un modelo de traducción o de apropiación creativa de los conceptos políticos secularizados: la teología política es la aniquilación del intento de despolitización del mundo moderno.

Los intentos de despolitización moderna se neutralizan en la medida que emergen formas múltiples de pensar la relación entre política y religión. El liberalismo desplaza la pregunta por esta relación y la convierte en una virtud

${ }^{36}$ El debate acerca del nacionalismo como una secularización de las creencias religiosas está en discusión. El lazo afectivo del nacionalismo comparte un parecido familiar con las religiones políticas, pero el nacionalismo puede ser la antípoda de la religión en la medida que opera como una sustitución de la religión civil. $C f$. Richard Bernstein, Civil Religion: A Dialogue in the History of Political Philosophy. Cambridge, Universidad de Cambridge, 2011.

${ }^{37}$ Los antimodernos son, en general, unos estetas que no mantienen una relación directa con la crítica a la modernidad política. En realidad, los antimodernos son unos modernos radicales, pues asumen que sólo el llevar la modernidad hasta sus últimas consecuencias es posible para cuidar el trabajo de la tradición. Antoine Compagnon argumentó: "Los verdaderos antimodernos son también, al mismo tiempo, unos modernos, aun y en todo momento unos modernos, o unos modernos a pesar de ellos mismos. Baudelaire es el prototipo, su modernidad -él inventó la noción- era inseparable de su resistencia al 'mundo moderno' [...] Los antimodernos - no los tradicionalistas- sino los antimodernos auténticos -no serían otros que los modernos, los verdaderos modernos, no embaucados por lo moderno, despabilados" (Antoine Compagnon, Los antimodernos. Barcelona, Acantilado, 2009, p. 34). 
moral: la tolerancia religiosa. Esto quiere decir que el liberalismo carece de un impacto simbólico porque es incapaz de producir un ethos de la obediencia política basado en el contrato social. El liberalismo desplaza la religión a la esfera privada y, por ende, la convierte en una virtud moral. En cambio, la teología política permite explicar las trasferencias conceptuales entre ambas esferas: si la monarquía corresponde con el monoteísmo, el republicanismo con el politeísmo, el anarquismo con el ateísmo, el constitucionalismo con el deísmo y el socialismo con el mesianismo. ${ }^{38}$ Esto implica, más que una correlación causal o un nexo conceptual, una prueba de que la forma de pensar la política coincide con las modalidades de la imaginación teológica. ${ }^{39}$ De manera que lo correcto es nombrar a estos casos como teologías políticas modernas, ya que responden a la pluralidad confesional y política del mundo moderno.

Finalmente, para probar que la era postsecular es una disputa entre las teologías políticas modernas y que la secularización es una de las formas mitológicas que adquiere la modernidad es necesario justificar dos puntos. Primero, el mito político debe explicarse de manera postsecular. Segundo, la secularización debe fundamentarse como uno de los mitos de la modernidad. Cabe precisar que la justificación del componente mitológico de la modernidad no implica necesariamente la defensa de una teología política ni una aceleración de las patologías políticas de la modernidad. Por el contrario, la defensa política del mito permite explicar la función normativa de la secularización en tanto que justifica, filosóficamente, el tránsito del teorema de la secularización hacia el mitologema de la modernidad. Es decir, el mito político permite explicar la sustitución de la tesis sociológica de Schmitt (los conceptos políticos son traducciones de los conceptos teológicos) por la tesis filosófica de Blumenberg (la ausencia de los fundamentos universales es una condición trascendental de la vida moderna), pero para poder explicar este tránsito es necesario desmontar la tesis postsecular de los nuevos teólogos de la política (la teoría política moderna es una teología disfrazada).

\section{El diagnóstico teológico de la modernidad}

Para el archivo filosófico del siglo xx, la discusión acerca de la institucionalización de la teología política tuvo tres momentos constituyentes. El primer momento ocurrió en la Alemania de la posguerra y estuvo vinculado directamente con el existencialismo, la fenomenología y la hermenéutica. El segundo

${ }^{38} \mathrm{Cf}$. A. Rivera García, El Dios de los tiranos. Un recorrido por los fundamentos teóricos del absolutismo, la contrarrevolución y el totalitarismo, p. 54.

${ }^{39} \mathrm{Cf}$. W. Cavanaugh, Theopolitical Imagination. Christian Practices of Space and Time. Nueva York, T\&T Clark, 2003. 
momento fue a partir de la década de los sesenta y tuvo en América Latina un alto impacto, sobre todo a partir de la fuerza social de la teología de la liberación. El tercer momento comenzó a darse a partir de la década de los noventa y tuvo dos frentes: por un lado, los teólogos anglosajones que empezaron a pensar el impacto político de lo teológico; por el otro, los pensadores italianos que discutieron el uso teológico de lo político. En este contexto, los filósofos italianos comenzaron a publicar libros de teoría política a partir de premisas teológicas. El ejemplo paradigmático de este estilo de filosofía es Giorgio Agamben o Roberto Esposito, para quienes la discusión de lo político depende de la crítica de lo teológico. ${ }^{40}$ Igualmente, en este periodo surgió la Radical Orthodoxy, una teología política autodenominada teología postsecular. ${ }^{41}$ Esta corriente teológica intentó recuperar la dimensión pública de la religión y mostrar que la teología en el siglo XXI puede convertirse, nuevamente, en la reina de las ciencias sin que por ello la teología se convierta en una práctica conservadora o que impida un tipo de saber emancipatorio. El representante más emblemático al respecto es el teólogo William Cavanaugh. Lo relevante radica en que el punto de unión entre la filosofía italiana contemporánea y la Radical Orthodoxy es que ambas realizan una crítica teológica a la modernidad, ya que localizan sus argumentos en un horizonte posliberal en el que es inevitable una vuelta a la religión. ${ }^{42}$

La Radical Orthodoxy propone una nueva teología política para los contextos postseculares y, para conseguirlo, explica a la modernidad como un mito político basado en el abandono del proyecto ilustrado. En efecto, John Milbank ${ }^{43}$ y William Cavanaugh ${ }^{44}$ plantearon una recuperación de la teología como una forma de imaginación política, puesto que ambos consideran que existe una aplicación directa de la teología a la teoría política y al derecho moderno. Tal información extravagante debe tomarse en cuenta, pues no se trata de una reivindicación metodológica de la teología política, como lo hizo Carl Schmitt en 1922, sino de un programa político que ha tomado fuerza institucional en los años recientes. La teología política de la postsecularización tiene en la Radical Orthodoxy el fundamento teórico para comenzar una discusión rigurosa acerca del retorno de la religión en el espacio público. La

${ }^{40} \mathrm{Cf}$. Roberto Esposito y Massimo Cacciari, Dialogo sulla teologia política. Micromega, núm. 2, marzo, 2014, pp. 3-25.

${ }^{41}$ Vid. James K. A. Smith, Introducing Radical Orthodoxy: Mapping a Post-secular Theology. Londres, Routledge, 2004.

${ }^{42}$ R. Esposito, Living Thought. The Origins and Actuality of Italian Philosophy. Stanford, Universidad de Stanford, 2012.

${ }^{43}$ John Milbank, Teología y teoría social. Más allá de la razón secular. Barcelona, Herder, 2004.

${ }^{44}$ W. Cavanaugh, "Is Public Theology Really Public? Some Problems with Civil Society", en Annual Society of Christian Ethics, enero, 2001, vol. 21, pp. 105-123. 
teología política es así el gesto constante del retorno de lo antimoderno. Si Schmitt es un antimoderno es porque realizó una crítica teológico-política a la neutralidad del liberalismo decimonónico y, por extensión, recuperó el planteamiento de los contrarrevolucionarios para promover una filosofía católica del Estado; ${ }^{45}$ análogamente, la Radical Orthodoxy es un gesto antimoderno radicalizado, puesto que en su crítica de la modernidad subyace un malestar en la Ilustración y, al igual que Schmitt, una crítica teológica al liberalismo de finales del siglo $\mathrm{xx}$.

En consecuencia, el retorno antimoderno de la teología política es básicamente una crítica a las promesas incumplidas de la Ilustración, el síntoma de una Ilustración fallida. William Cavanaugh, quizá el teólogo más radical al respecto, elaboró una teología anti-ilustrada en la que intenta superponer la religión a la política. En Theopolitical Imagination (2002), Cavanaugh sostiene que la teopolítica -término que acuñó para unir lo teológico con lo político-indica que la separación estricta entre la teología y la política es una invención moderna y no una forma natural del mundo social. Asimismo, la estrategia de producción de categorías binarias -religioso/secular, naturaleza/gracia, teología/política-es la operación epistemológica básica de la modernidad y, por ende, constituye sólo una forma de imaginar el mundo. Las categorías de la modernidad imaginan un mundo posible más que describirlo con certeza. La aceptación de esos imaginarios como fenómenos reales produce una forma de mistificación. La modernidad está apoyada así en múltiples mitologías provenientes de esta clasificación binaria del mundo. Por esta razón, Cavanaugh concluye que las categorías políticas de la modernidad son un tipo de soteriología.

La soteriología es una categoría teológica, no política. La soteriología responde al problema de la salvación y según la confesión religiosa será el tipo de salvación política. Por ejemplo, para la teoría política liberal, cuyo origen teológico es el protestantismo anglosajón, la acción del individuo puede salvar la comunidad política únicamente si las acciones tienen un impacto público y si queda protegida la esfera privada. Según Cavanaugh, el liberalismo al negar las implicaciones teológicas de su formación política confirma el mito de la sociedad civil como un espacio libre y autónomo. La sociedad civil es así el mito moderno del espacio libre porque la sociedad civil designa un espacio que es público sin ser político: la distinción público-privado es la categoría binaria que sirvió al Estado para domesticar a la Iglesia, para evitar la inclusión política de los fieles. ${ }^{46}$

${ }^{45}$ Cabe recordar que la filosofía católica del Estado le sirvió a Schmitt para justificar una teoría de la autoridad política basada en la representación, el carisma y el decisionismo jurídico. C. Schmitt, Catolicismo y forma política. Barcelona, Tecnos, 1998.

46 W. Cavanaugh, Theopolitical Imagination. Christian Practices of Space and Time, p. 54. 
A diferencia de las reflexiones de la escuela de Frankfurt, la razón de la crítica virulenta a la Ilustración por parte de la Radical Orthodoxy reside en los axiomas con los cuales evalúan el mundo moderno: la religión es el baremo para medir el impacto civilizatorio. La modernidad es así "el sistema, tanto ideológico como material, que, habiendo comenzado en Occidente y habiéndose extendido después a muchas otras regiones del mundo, está basado en la exclusión de lo divino de la vida pública". ${ }^{47} \mathrm{Si}$ el ocultamiento de la fuerza pública-religión constituye uno de los puntos ciegos de la modernidad, entonces el mito de la Ilustración reside en la creencia de que la religión pertenece a la esfera privada y, por lo tanto, que es posible eliminarla como parte de las necesidades antropológicas del ser humano. "El mito afirma que las formas previas de civilización habían mezclado equivocadamente esos términos [religioso/secular] en una especie de confusión pre-ilustrada", ${ }^{48}$ La rehabilitación de la religión es la prueba de la retirada de la Ilustración. Por consiguiente, el mito de la modernidad consiste en la reproducción de las categorías binarias para pensar el mundo y la Ilustración es el tipo de imaginación política que asume la identidad ontológica entre estos códigos binarios.

Para deconstruir la mitología de la modernidad y probar los efectos teológicos de la Ilustración, Cavanaugh establece tres puntos de crítica. Primero, realiza una crítica teológica a la modernidad. La modernidad no es anti-teológica, más bien es una mala teología. Segundo, recupera la noción de la teología como reina de las ciencias. La teología puede aspirar, en el siglo XXI, a fungir como un discurso integrador de las ciencias y las humanidades, ya que la teoría social moderna es una teología disfrazada. Tercero, postula la ineficacia histórica del mito del Estado. La teoría del Estado moderno es una teología política basada en la lógica sacrificial.

Respecto del primer punto, Cavanaugh destacó la dimensión normativa de la teología y realizó una crítica teológica a la teología moderna: ni la escolástica católica ni la teología de la liberación son capaces de enfrentar con radicalidad las estructuras mitológicas de la modernidad porque en el fondo son teologías con improntas ilustradas y activan, inevitablemente, los códigos binarios de la modernidad. El mito que preserva estas teologías es el mito de la religión como parte de la esfera privada del ser humano. El error reside en aceptar un supuesto no justificado del relato weberiano acerca de la modernidad: la religión como una actividad humana es irracional y propensa a la violencia. Si en el relato weberiano el Estado tiene el monopolio de la violencia legítima porque es el instrumento que sirvió históricamente para domeñar las pasiones religiosas provenientes de las divisiones entre católicos y protestantes, entonces el pro-

${ }^{47}$ W. Cavanaugh, "La mitología de la modernidad: un diagnóstico teológico", en op. cit., p. 14.

${ }^{48}$ Idem. 
blema reside en que el Estado aparece justificado como un ente pacificador, ya que estuvo amparado en un actor "soberano religiosamente neutral", ${ }^{49}$ lo cual es históricamente falso. Ningún Estado moderno, asegura Cavanaugh, es religiosamente neutral ni tampoco está libre de supuestos políticos confesionales. Por el contrario, la formación del Estado moderno implicó la subordinación del poder religioso al poder civil, pero nunca la eliminación de este último como elemento configurante del orden social.

El segundo punto crítico subraya que para que el Estado-nación triunfara en el mundo moderno fue necesario marginar a la teología como disciplina integradora. La teoría positivista de la unidad de las ciencias o el ideal weberiano de unificación de las ciencias sociales son la prueba de esta marginación, pues ni la sociología ni la filosofía ni las ciencias cognitivas han podido elaborar una teoría de la unidad basada en un discurso de integración del cúmulo de saberes científicos y humanísticos. La teología fue relegada como un ámbito de saber legítimo, más que por el impulso positivista de la ciencia empírica, por el triunfo de la teología de la modernidad. La modernidad tiene una base teológica, pero esta teología es una mala teología. Siguiendo a Milbank, Cavanaugh sostiene que la teoría social moderna, aunque tiene la pretensión de objetividad y racionalidad, es una teología encubierta. De manera que el problema no es que la modernidad tenga un remanente teológico o que sea una teología secularizada, sino que el discurso filosófico de la modernidad está basado en una teología deficiente. El reinventar la modernidad, imaginarla de manera diferente a la forma ilustrada, supone una política basada en otra teología: una teología de la creación y redención política.

Asimismo, para ilustrar el lado teológico de las ciencias sociales, ${ }^{50}$ Cavanaugh argumenta que la economía clásica de origen liberal está basada en una "teología inmanentizada de la creación": los seres humanos crean los bienes para transformar la naturaleza basándose en la libertad y existe un lenguaje providencial para elaborar una teodicea del mercado. El problema de la economía clásica fue que no pudo emanciparse de la teología y, por el contrario, contribuyó a un giro económico dentro de la teología. La economía clásica es una teología propietarista y el mercado es el interventor sacramental. Igualmente, la teoría política moderna es una forma de teología encubierta. Hobbes, por ejemplo, sustituyó la teología participativa del corporativismo medieval por una teología de la voluntad basada en la formación de la soberanía moderna. Locke enfrentó la teología monárquica de Robert Filmer para postular una teología benedictina de la salvación por medio del trabajo. Incluso,

${ }^{49}$ Ibid., p. 24.

${ }^{50}$ J. Milbank, Teología y teoría social. Más allá de la razón secular. Barcelona, Herder 2004. 
en las democracias liberales contemporáneas, la cohesión social depende de una religión civil mantenida a partir de una ritualización de la ciudadanía y de un lazo carismático con la nación. ${ }^{51}$ Por consiguiente, si la economía de mercado y el liberalismo político tienen un fundamento teológico, pero en su intento de conjura teológica intentan fallidamente secularizar su discurso, el resultado es una teología encubierta apoyada en supuestos teóricos no justificados: las ciencias sociales suponen la creencia en una dogmática de la acción racional. La propuesta de Cavanaugh es convertir a la teología en una disciplina integradora, la reina de las ciencias, pues es capaz de articular la naturaleza y la gracia para así ofrecer una visión omnicomprensiva del ser humano y de todo lo que le rodea.

El último punto explica por qué el Estado-nación adoptó una estructura religiosa, pues para obtener legitimidad histórica tuvo que emplear los recursos de obediencia propios de los aparatos confesionales, con los cuales la lógica sacrificial de la teología medieval fue trasladada al campo político de lo moderno. "La gradual transferencia de fidelidad de la Iglesia internacional al Estado nacional no supuso el final de la violencia en Europa, sino una transferencia de sacralidad de la Iglesia al Estado". ${ }^{52}$ Incluso, el Estado-nación, que tuvo en la formulación de Hobbes su máxima expresión teológica -el Leviatán como un dios mortal- es la prueba de que la política moderna es una extensión de la teología, ya que se "sobrenaturalizó lo natural" y de esta forma comenzó una competencia entre la autoridad teológica del poder civil y la legitimidad política del poder religioso.

En suma, la rehabilitación de la teología política es más que un síntoma de los problemas no resueltos por la cultura ilustrada: representa un diagnóstico de los grados de secularidad de la conciencia moderna. Si la secularización es un programa por venir, un proyecto ilustrado que requiere de una activación histórica constante, entonces es necesario evitar los prejuicios que los liberales ilustrados no pudieron anticipar: la importancia política de los mitos y la religión. Sin un cuidado político de estos elementos, y sin una protección institucional por los derechos religiosos, el fundamentalismo puede activar los mecanismos mitológicos con los cuales se construyen las disposiciones afectivas y simbólicas del poder político. Por consiguiente, el retorno del pensamiento antimoderno sólo es posible en un contexto postsecular, un contexto que requiere, nuevamente, de demostrar la necesidad de una nueva cultura política ilustrada.

${ }^{51}$ Robert Bellah, Habits of the Heart. Individualism and Commitment in American Life. Los Angeles, Universidad de California, 1985.

52 W. Cavanaugh, "La mitología de la modernidad: un diagnóstico teológico", en op. cit., p. 25. 